\title{
Update on Rabies Diagnosis and Treatment
}

\author{
Alan C. Jackson, $M D$
}

\author{
Corresponding author \\ Alan C. Jackson, MD \\ Departments of Internal Medicine (Neurology) and Medical \\ Microbiology, University of Manitoba and Health Sciences \\ Centre, GF-543, 820 Sherbrook Street, Winnipeg, Manitoba \\ R3A 1R9, Canada. \\ E-mail: ajackson2@hsc.mb.ca \\ Current Infectious Disease Reports 2009, 11:296-301 \\ Current Medicine Group LLC ISSN 1523-3847 \\ Copyright $@ 2009$ by Current Medicine Group LLC
}

The diagnosis of rabies depends on recognizing the clinical picture, because a history of an animal bite may be present or absent. Laboratory tests, particularly when based on detection of rabies virus antigen or RNA in tissues or fluids, often confirm the diagnosis. Negative laboratory tests do not exclude the diagnosis unless they are performed on brain tissues. Preventive therapy, including wound cleansing and active and passive immunization after a recognized exposure, is well established and highly efficacious. No established therapy exists that is effective for patients with rabies encephalomyelitis. The Milwaukee protocol involves induction of therapeutic coma; however, there is no clear rationale for a neuroprotective role of this therapy, many reports exist of its failures, and its use should be abandoned. Basic research is needed on the mechanisms of rabies pathogenesis. This may allow the development of new therapeutic approaches for this ancient disease.

\section{Introduction}

Globally about 55,000 human cases of rabies occur each year, largely related to transmission of endemic dog rabies in developing countries [1]. In North America, rabies is found in wildlife, including bats, raccoons, skunks, and foxes, and relatively few human cases occur. Rabies virus transmission almost always occurs following animal bites. Transmission from aerosols in the laboratory or in caves containing millions of bats is very rare; transmission has also rarely occurred in association with corneal

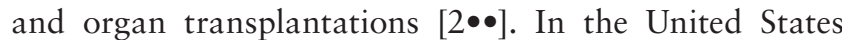
and Canada, most human cases are caused by bat rabies variants, and many of these are from unrecognized bat exposures. Patients who develop rabies face a very dismal outcome. Although it is unclear why an American girl survived rabies in 2004, this outcome offers hope that aggressive approaches to therapy may become more successful in the future. Unfortunately, no effective therapy for rabies is available now. An improved understanding of the pathogenesis of rabies may be helpful in the future design of novel therapies for this ancient disease.

\section{Diagnosis of Rabies \\ Clinical overview}

In North America and Europe, a diagnosis of rabies is often not made until relatively late in the clinical course or after death, in part because physicians are not familiar with the disease and may not recognize even typical clinical features. In the United States and Canada, the absence of a history of an animal bite is common in fatal cases, particularly because bat bites may not be recognized [3]. Sometimes there is a history of exposure to bats, but no history of direct contact. Insectivorous bats are small and their bites are not easily recognized or may be attributed to insects. Rabies usually develops 1 to 3 months after an exposure; rarely, the incubation period can be as short as a few days or more than a year after the exposure. Prodromal symptoms are nonspecific and may last a few days; these include fever, chills, malaise, fatigue, insomnia, anorexia, headache, anxiety, and irritability. About half of patients develop pain, paresthesias, or pruritus at or close to the bite site, which likely reflects infection in local dorsal root ganglia [4]. The two clinical forms of rabies are encephalitic (furious) in $80 \%$ and paralytic (dumb) in $20 \%$ of patients; however, the underlying pathogenetic mechanisms are poorly defined [5]. In the encephalitic form, patients have episodes of generalized arousal or hyperexcitability separated by lucid periods [6]. They may have aggressive behavior, confusion, and hallucinations. Fever is common and signs of autonomic dysfunction, including hypersalivation, sweating, piloerection, and priapism (in males) may be present. About $50 \%$ to $80 \%$ of patients develop hydrophobia, which is a characteristic manifestation of rabies. Patients may initially experience pain in the throat or difficulty swallowing. On attempting to swallow, they experience contractions of the diaphragm and other inspiratory muscles, which last about 5 to 15 seconds. Subsequently, the sight, sound, or even mention 
of water (or any liquids) may trigger the spasms. A draft of air on the skin may have the same effect (ie, aerophobia). The disease may progress through paralysis, coma, multiple organ failure, and eventually death. Viral encephalitis caused by other viruses is generally associated with earlier impairment of consciousness compared with rabies, with less prominent early evidence of brainstem involvement.

In paralytic rabies, flaccid muscle weakness develops early in the disease course, often beginning in the bitten extremity and spreading to the other extremities and facial muscles. Sphincter involvement, pain, and sensory disturbances also occur. Hydrophobia is unusual, although bulbar and respiratory muscles eventually become involved. Patients with paralytic rabies typically survive longer than those with the encephalitic form, and the condition may be misdiagnosed as an inflammatory polyneuropathy (eg, Guillain-Barré syndrome) or a spinal cord disorder.

Recognition of the clinical picture with or without a history of an animal exposure is paramount in the diagnosis of rabies. Laboratory tests should be used to confirm a clinical suspicion (see below).

\section{Investigations}

CT scans of the head are usually normal in patients with rabies. Experience is limited with MR imaging, although normal studies and increased signals in gray matter areas have been observed [7-11]. Increased signals on T2weighted images in the medulla and pons were observed in an American case in which disease was associated with a bat rabies virus variant [12]. Characteristic differences in MR findings in the brain and spinal cord of encephalitic and paralytic rabies cases have not been recognized [13].

Cerebrospinal fluid (CSF) analysis results are often abnormal in rabies. Anderson et al. [14] found a CSF pleocytosis in $59 \%$ of cases during the first week of illness and in $87 \%$ of cases after the first week. The CSF white blood cell count is usually less than 100 cells/ $\mu \mathrm{L}$ and mononuclear cells predominate. The CSF protein concentration may be mildly elevated and the glucose concentration is usually normal. Serum-neutralizing antibodies against rabies virus are not usually present in unimmunized patients until after the 10th day of illness [4], and death may occur before they develop. Early in the illness, rabies virus may occasionally be isolated from the saliva or CSF [14]. A skin biopsy may confirm a diagnosis of rabies during life, with rabies virus antigen detected in skin biopsies using the fluorescent antibody technique [15]. Antigen may be demonstrated in small nerves of skin taken from the nape of the neck, which is rich in hair follicles; detection of antigen in corneal impression smears is less sensitive than skin biopsies [15]. Diagnosis of rabies using a brain biopsy is usually unnecessary, but brain tissues can be assessed postmortem for rabies virus antigen and viral isolation. Small amounts of rabies virus RNA may be amplified from saliva, skin, CSF, and brain using reverse transcription-polymerase chain reac- tion (RT-PCR). This technique has proved an important advance in the diagnosis of rabies. Of 20 human rabies cases diagnosed antemortem in the United States between 1980 and 1996, rabies virus RNA, using RT-PCR, was detected in saliva from all 10 patients who had the test performed, including three who had negative viral isolation from saliva [16]. A recent study showed a higher specificity $(100 \%)$ and sensitivity $(\geq 98 \%)$ of RT-PCR (heminested protocol) on skin biopsy specimens than on saliva specimens, although saliva is much easier to collect and sensitivity on saliva was $100 \%$ when three successive samples were analyzed [17•]. Negative tests for rabies virus antigen or RNA do not exclude rabies unless performed on brain tissues. Repeat specimens may need to be collected and tested to confirm a diagnosis of rabies.

\section{Treatment of Human Rabies \\ Postexposure prophylaxis}

Rabies can be prevented very effectively after a recognized exposure. It is important to closely follow current recommendations for rabies prevention, which are available on the websites of the Centers for Disease Control and Prevention's Morbidity and Mortality Weekly Report (http://www.cdc.gov/mmwr/) and World Health Organization (http://www.who.int/en/), because even minor deviations can lead to failure $[1,18 \bullet \bullet]$. After a human is bitten by a dog, cat, or ferret, the animal should be captured, confined, observed for at least 10 days, and examined by a veterinarian before its release. If the animal is a stray or unwanted, or if signs of rabies are present or develop during the observation period, the animal should be killed and the head transported under refrigeration for laboratory examination. The brain should be examined for the presence of rabies virus, usually via an antigendetection method using the fluorescent antibody technique and viral isolation using cell culture or mouse inoculation. The incubation period for animals other than dogs, cats, and ferrets is uncertain; hence, they should be killed immediately after an exposure and the head submitted for laboratory examination. If the result is negative, one may safely conclude that the animal's saliva did not contain rabies virus and, if immunization was initiated, it should be discontinued. If an animal escapes after an exposure, it should be considered rabid and rabies prophylaxis should be initiated, unless information from public health officials indicates rabies is unlikely. The physical presence of a bat may warrant postexposure prophylaxis when a person (eg, a small child or sleeping adult) is unable to reliably report contact that could have resulted in a bite, although this recommendation is controversial $[18 \bullet \bullet, 19 \bullet \bullet]$.

Effective postexposure therapy includes wound cleansing, and active and passive immunization in a previously unimmunized individual $[18 \bullet \bullet$. Active immunization is achieved with five doses of a modern cell culture vaccine, including purified chick embryo cell culture vaccine or human diploid cell vaccine (administered intramuscularly 
in the deltoid muscle on days $0,3,7,14$, and 28). Passive immunization is performed with human rabies immune globulin at a dosage of $20 \mathrm{IU} / \mathrm{kg}$ with local infiltration into and around the wound(s); any remaining dose should be given intramuscularly into the gluteal area.

\section{Treatment of rabies encephalomyelitis}

The ideal therapy for a patient with rabies is unknown. Until recently, only patients who received rabies vaccine before the onset of disease have survived [2]. Several approaches have not proved successful. Therapy with human leukocyte interferon, given as high-dose intraventricular and systemic (intramuscular) administration, in three patients was not associated with a beneficial clinical effect, but this therapy was not initiated until between 8 and 14 days after the onset of symptoms [20]. Similarly, antiviral therapy with intravenous ribavirin, 16 to 400 $\mathrm{mg}$, in 16 patients was unsuccessful in China [21]. An open trial of therapy with combined intravenous and intrathecal administration of either ribavirin (one patient) or interferon- $\alpha$ (three patients) was also unsuccessful [22]. Anti-rabies virus hyperimmune serum of either human or equine origin has been administered intravenously and intrathecally, but there was no beneficial effect [23-26].

A group consisting of physicians with expertise in rabies and other rabies researchers published an article in 2003 giving recommendations on therapies to consider for an aggressive approach [27]. Young and previously healthy patients with an early clinical diagnosis of rabies (before laboratory confirmation) and prompt initiation of therapy should offer the best opportunity for a favorable outcome [27]. Therapies for potential consideration include rabies vaccine, human rabies immune globulin, monoclonal antibodies (in the future), ribavirin, interferon- $\alpha$, and ketamine. The recommendation for therapy with ketamine was based on animal studies performed at the Pasteur Institute in Paris [28]. As with current therapies for cancer, HIV infection, and chronic hepatitis $\mathrm{C}$ infection, it was believed that a combination of therapies might prove effective in situations where specific therapies had failed.

In 2004 , a patient survived rabies who had not received rabies vaccine before the onset of clinical disease [29]. This 15 -year-old female was bitten by a bat on her left index finger; the wound was washed with peroxide, but she did not seek medical attention or receive any other treatment at that time. About 1 month after the bite, she developed numbness and tingling of her left hand, and over the next 3 days developed diplopia, bilateral partial sixth-nerve palsies, and unsteadiness. An MR imaging study of the brain was normal. On her fourth day of illness, CSF examination showed a pleocytosis (23 white blood cells/ $\mu \mathrm{L}$, predominantly lymphocytes) and mildly elevated protein. She subsequently developed fever $\left(38.8^{\circ} \mathrm{C}\right)$, nystagmus, left arm tremor, and hypersalivation; the history of the bat bite was obtained at this time. The patient was transferred to a tertiary care hospital in Milwaukee, WI, 5 days after the onset of neurologic symptoms. Neutralizing anti-rabies virus antibodies were detected in sera and CSF (initially at a titer of 1:32). Nuchal skin biopsies were negative for rabies virus antigen, rabies virus RNA was not detected in the skin biopsies or in saliva by RT-PCR, and viral isolation on saliva was negative. The patient was intubated and put into a drug-induced coma, which included the noncompetitive $\mathrm{N}$-methyl-D-aspartate antagonist ketamine, $48 \mathrm{mg} / \mathrm{kg} / \mathrm{d}$ administered as a continuous infusion, and intravenous midazolam for 7 days. A burst-suppression pattern on her electroencephalogram was maintained and supplemental phenobarbital was given. She also received antiviral therapy, including intravenous ribavirin and amantadine, $200 \mathrm{mg} / \mathrm{d}$ administered enterally. She improved and was discharged from the hospital with neurologic deficits, but subsequently showed progressive neurologic improvement [30].

This is the first documented survivor who had not received rabies vaccine before the onset of clinical rabies. As discussed in an accompanying editorial, it is unknown if therapy with one or more specific agents played an important role in this patient's favorable outcome [31]. However, since then, at least 13 known cases were documented in which the main components of this approach (the "Milwaukee" protocol) were used, and fatal outcomes resulted (Table 1). There is also evidence that this protocol was used in additional cases and perhaps many others, but the details are not known and may never be reported [32]. The induction of coma has not proved useful in the management of infectious diseases of the nervous system, and there is no evidence supporting this approach in rabies or other viral encephalitides. Hence, therapeutic coma should not become a routine therapy for the management of rabies. Unlike other viral infections of the nervous system, including Sindbis virus encephalomyelitis and HIV infection, no established experimental evidence supports excitotoxicity in rabies and recent evidence in an animal model demonstrated the lack of efficacy of ketamine therapy, arguing against this hypothesis [33-37]. Even with strong experimental evidence of excitotoxicity in animal models, multiple clinical trials in humans showed a lack of efficacy of neuroprotective agents in stroke $[38,39]$. Hence, a strong neuroprotective effect of a therapy given to a single patient without a clear scientific rationale is probably not responsible for a favorable outcome. It is much more likely that this patient would have recovered with only supportive therapy and did well to tolerate the additional "insult" of therapeutic coma without significant adverse effects.

The presence of neutralizing anti-rabies virus antibodies early in a patient's clinical course is likely an important factor contributing to a favorable outcome. This probably occurs in less than $20 \%$ of all patients with rabies. The presence of neutralizing anti-rabies virus antibodies is a marker of an active adaptive immune response essential for viral clearance [40]. Six survivors of rabies received rabies vaccine before the onset of their disease (in contrast, only one survivor did not receive vaccine). This supports the notion that an early immune response is associated with a positive outcome. Bat rabies viruses may be less 


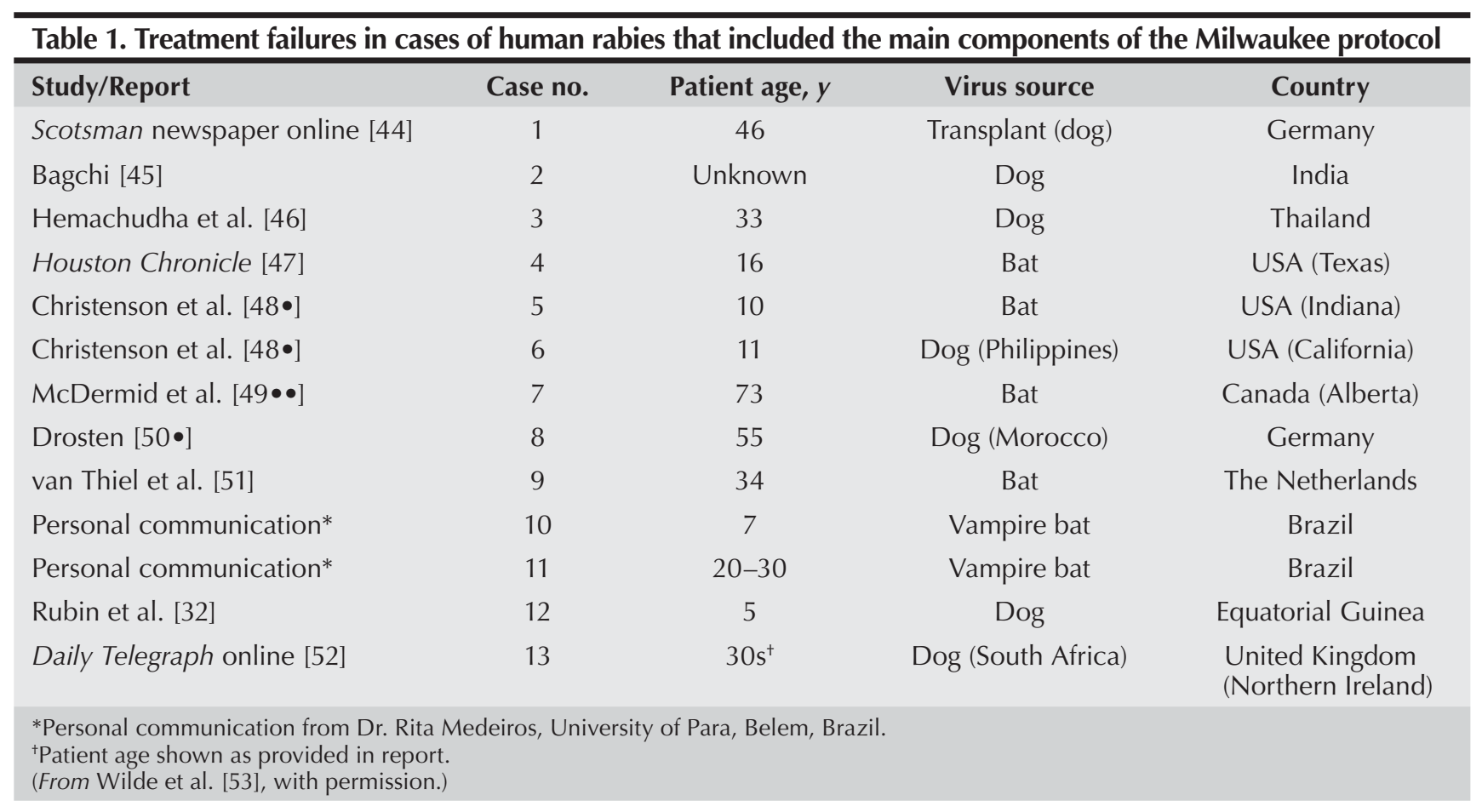

neurovirulent than canine or other variants responsible for most human cases of rabies, and rabies due to canine rabies virus variants may have a less favorable outcome than cases caused by bat rabies variants [41]. A previous survivor of rabies, who received rabies vaccine before the onset of disease, had a good neurologic recovery and was also infected with a bat rabies virus [42]. It is unknown if the causative bat rabies virus variant in the Milwaukee case was in some way attenuated and different from previously isolated strains because viral isolation was not successful. In another case with transmission of rabies from a vampire bat in Brazil, the patient received rabies vaccine before the onset of disease and was also treated with the Milwaukee protocol; this was reported only in preliminary form [43•]. Finally, most survivors of rabies have shown neutralizing anti-rabies virus antibodies in sera and CSF, but other diagnostic laboratory tests are usually negative for rabies virus antigen and RNA in fluids and tissues (brain tissues were not tested). This may be because viral clearance was so effective that centrifugal spread of the infection to peripheral organ sites was reduced or very rapid clearance occurred through immune-mediated mechanisms.

\section{Conclusions}

The diagnosis of rabies should be based on a high index of clinical suspicion and confirmed with laboratory tests, including techniques for detecting rabies virus antigen or RNA and serologic testing for neutralizing anti-rabies virus antibodies. In particular, RT-PCR for the detection of rabies virus RNA in saliva and skin biopsies was an important advance for the antemortem laboratory diagnosis of human rabies and often allows confirmation of the diagnosis before death.
Rabies can be prevented after recognized exposures, but no effective therapy for human rabies is available. It remains highly doubtful that the Milwaukee protocol will prove useful in the management of human rabies. Unfortunately, promotion and repetition of this therapy may impede progress in developing new effective therapies for rabies. More basic research is needed to improve our understanding of the mechanisms underlying rabies pathogenesis in humans and animals. This may allow the development of new therapeutic approaches for the management of this ancient disease.

\section{Disclosure}

No potential conflict of interest relevant to this article was reported.

\section{References and Recommended Reading}

Papers of particular interest, published recently, have been highlighted as:

\section{- Of importance}

-• Of major importance

1. World Health Organization: WHO Expert Consultation on Rabies: First Report. Geneva, Switzerland: WHO; 2005.

2.• Jackson AC: Human disease. In Rabies, edn 2. Edited by Jackson AC, Wunner WH. London: Elsevier Academic Press; 2007:309-340.

This review comprehensively evaluates what is known about the clinical manifestations, differential diagnosis, diagnosis, and therapy of human rabies.

3. Messenger SL, Smith JS, Rupprecht CE: Emerging epidemiology of bat-associated cryptic cases of rabies in humans in the United States. Clin Infect Dis 2002, 35:738-747.

4. Hattwick MAW: Human rabies. Public Health Rev 1974, $3: 229-274$. 
5. Jackson AC: Pathogenesis. In Rabies, edn 2. Edited by Jackson AC, Wunner WH. London: Elsevier Academic Press; 2007:341-381.

6. Warrell DA: The clinical picture of rabies in man. Trans $R$ Soc Trop Med Hyg 1976, 70:188-195.

7. Sing TM, Soo MY: Imaging findings in rabies. Australas Radiol 1996, 40:338-341.

8. Mrak RE, Young L: Rabies encephalitis in a patient with no history of exposure. Hum Pathol 1993, 24:109-110.

9. Hantson P, Guerit JM, de Tourtchaninoff M, et al.: Rabies encephalitis mimicking the electrophysiological pattern of brain death. A case report. Eur Neurol 1993, 33:212-217.

10. Awasthi M, Parmar H, Patankar T, Castillo M: Imaging findings in rabies encephalitis. AJNR Am J Neuroradiol 2001, 22:677-680.

11. Mani J, Reddy BC, Borgohain R, et al.: Magnetic resonance imaging in rabies. Postgrad Med J 2003, 79:352-354.

12. Pleasure SJ, Fischbein NJ: Correlation of clinical and neuroimaging findings in a case of rabies encephalitis. Arch Neurol 2000, 57:1765-1769.

13. Laothamatas J, Hemachudha T, Mitrabhakdi E, et al.: MR imaging in human rabies. AJNR Am J Neuroradiol 2003, 24:1102-1109.

14. Anderson LJ, Nicholson KG, Tauxe RV, Winkler WG: Human rabies in the United States, 1960 to 1979: epidemiology, diagnosis, and prevention. Ann Intern Med 1984, 100:728-735.

15. Warrell MJ, Looareesuwan S, Manatsathit S, et al.: Rapid diagnosis of rabies and post-vaccinal encephalitides. Clin Exp Immunol 1988, 71:229-234.

16. Noah DL, Drenzek CL, Smith JS, et al.: Epidemiology of human rabies in the United States, 1980 to 1996. Ann Intern Med 1998, 128:922-930.

17. Dacheux L, Reynes JM, Buchy P, et al.: A reliable diagnosis of human rabies based on analysis of skin biopsy specimens. Clin Infect Dis 2008, 47:1410-1417.

This study thoroughly examines RT-PCR for rabies diagnosis on skin biopsies and saliva specimens.

18.• Manning SE, Rupprecht CE, Fishbein D, et al.: Human rabies prevention-United States, 2008: recommendations of the Advisory Committee on Immunization Practices. MMWR Morb Mortal Wkly Rep 2008, 57(No. RR-3):1-28.

This up-to-date document gives detailed recommendations

concerning the prevention of human rabies.

19.• Huot C, De SG, Duval B, et al.: The cost of preventing rabies at any cost: post-exposure prophylaxis for occult bat contact. Vaccine 2008, 26:4446-4450.

This important paper indicates present recommendations concerning possible bat exposures (eg, in bedroom) may be associated with a very low level of risk and prophylaxis may not be cost effective.

20. Merigan TC, Baer GM, Winkler WG, et al.: Human leukocyte interferon administration to patients with symptomatic and suspected rabies. Ann Neurol 1984, 16:82-87.

21. Kureishi A, Xu LZ, Wu H, Stiver HG: Rabies in China: recommendations for control. Bull World Health Organ 1992, 70:443-450.

22. Warrell MJ, White NJ, Looareesuwan S, et al.: Failure of interferon alfa and tribavirin in rabies encephalitis. $\mathrm{Br}$ Med J 1989, 299:830-833.

23. Hemachudha T, Sunsaneewitayakul B, Mitrabhakdi E, et al.: Paralytic complications following intravenous rabies immune globulin treatment in a patient with furious rabies [letter]. Int J Infect Dis 2003, 7:76-77.

24. Emmons RW, Leonard LL, DeGenaro F Jr, et al.: A case of human rabies with prolonged survival. Intervirology 1973, 1:60-72.

25. Hattwick MA, Corey L, Creech WB: Clinical use of human globulin immune to rabies virus. J Inf Dis 1976, 133(Suppl): A266-A272.

26. Basgoz N, Frosch MP: Case records of the Massachusetts General Hospital: a 32-year-old woman with pharyngeal spasms and paresthesias after a dog bite. N Engl J Med 1998, 339:105-112.
27. Jackson AC, Warrell MJ, Rupprecht CE, et al.: Management of rabies in humans. Clin Infect Dis 2003, 36:60-63.

28. Lockhart BP, Tsiang H, Ceccaldi PE, Guillemer S: Ketamine-mediated inhibition of rabies virus infection in vitro and in rat brain. Antivir Chem Chemother 1991, 2:9-15.

29. Willoughby RE Jr, Tieves KS, Hoffman GM, et al.: Survival after treatment of rabies with induction of coma. N Engl J Med 2005, 352:2508-2514.

30. Hu WT, Willoughby RE Jr, Dhonau H, Mack KJ: Longterm follow-up after treatment of rabies by induction of coma [letter]. N Engl J Med 2007, 357:945-946.

31. Jackson AC: Recovery from rabies [editorial]. N Engl J Med 2005, 352:2549-2550.

32. Rubin J, David D, Willoughby RE Jr, et al.: Applying the Milwaukee Protocol to treat canine rabies in Equatorial Guinea. Scand J Infect Dis 2009, 41:372-375.

33. Nargi-Aizenman JL, Havert MB, Zhang M, et al.: Glutamate receptor antagonists protect from virus-induced neural degeneration. Ann Neurol 2004, 55:541-549.

34. Darman J, Backovic S, Dike S, et al.: Viral-induced spinal motor neuron death is non-cell-autonomous and involves glutamate excitotoxicity. J Neurosci 2004, 24:7566-7575.

35. Nargi-Aizenman JL, Griffin DE: Sindbis virus-induced neuronal death is both necrotic and apoptotic and is ameliorated by $\mathrm{N}$-methyl-D-aspartate receptor antagonists. J Virol 2001, 75:7114-7121.

36. Nath A, Haughey NJ, Jones M, et al.: Synergistic neurotoxicity by human immunodeficiency virus proteins Tat and gp120: protection by memantine. Ann Neurol 2000, 47:186-194.

37. Weli SC, Scott CA, Ward CA, Jackson AC: Rabies virus infection of primary neuronal cultures and adult mice: failure to demonstrate evidence of excitotoxicity. J Virol 2006, 80:10270-10273.

38. Cheng YD, Al-Khoury L, Zivin JA: Neuroprotection for ischemic stroke: two decades of success and failure. NeuroRx 2004, 1:36-45.

39. Ginsberg MD: Current status of neuroprotection for cerebral ischemia: synoptic overview. Stroke 2009, 40(Suppl 3):S111-S114.

40. Lafon M: Immunology. In Rabies, edn 2. Edited by Jackson AC, Wunner WH. London: Elsevier Academic Press; 2007:489-504.

41. Lafon M: Bat rabies-the Achilles heel of a viral killer? Lancet 2005, 366:876-877.

42. Hattwick MAW, Weis TT, Stechschulte CJ, et al.: Recovery from rabies: a case report. Ann Intern Med 1972, 76:931-942.

43.- Ministerio da Saude in Brazil: Rabies, human survival, bat-Brazil (Pernambuco). ProMED-mail Web site; 20081114.3599. Available at http://www.promedmail.org. Accessed February 2009.

This Pro-MED mail post is a preliminary report of survival from rabies after exposure to a vampire bat in which rabies vaccine was given before illness developed.

44. Scotsman newspaper online: Rabies, human, organ transplantation-Germany: third rabies-infected transplant patient dies. ProMED-mail Web site; 20050407.0998. Available at http://www.promedmail.org. Accessed February 2009.

45. Bagchi S: Coma therapy. The Telegraph-Calcutta. July 4, 2005. Available at http://www.telegraphindia. com/1050704/asp/knowhow/story_4936435.asp. Accessed April 2009.

46. Hemachudha T, Sunsaneewitayakul B, Desudchit T, et al.: Failure of therapeutic coma and ketamine for therapy of human rabies. J Neurovirol 2006, 12:407-409.

47. Houston Chronicle: Rabies, human-USA (Texas). ProMED-mail Web site; 20060513.1360. Available at http://www.promedmail.org. Accessed February 2009.

48.• Christenson JC, Holm BM, Lechlitner S, et al.: Human rabies-Indiana and California, 2006. MMWR Morb Mortal Wkly Rep 2007, 56:361-365.

This article describes US human rabies cases with failure of the Milwaukee protocol. 
49.• McDermid RC, Saxinger L, Lee B, et al.: Human rabies encephalitis following bat exposure: failure of therapeutic coma. Can Med Assoc J 2008, 178:557-561.

This article describes a Canadian human rabies case with failure of the Milwaukee protocol.

50. Drosten C: Rabies-Germany (Hamburg) ex Morocco. ProMED-mail Web site; 20070419.1287. Available at http://www.promedmail.org. Accessed February 2009. This Pro-MED mail post describes a case of human rabies due to Duvenhage virus with failure of the Wisconsin/Milwaukee protocol.
51. van Thiel PP, van den Hoek JAR, Eftimov F, et al.: Fatal case of human rabies (Duvenhage virus) from a bat in Kenya: the Netherlands, December 2007. Euro Surveill 2008, 13:118-119.

52. Daily Telegraph online: Rabies, human-United Kingdom (04): (Northern Ireland) ex South Africa. ProMED-mail Web site; 20090107.0065. Available at http://www.promedmail.org. Accessed April 2009.

53. Wilde H, Hemachudha T, Jackson AC: Viewpoint: management of human rabies. Trans $R$ Soc Trop Med Hyg 2008, 102:979-982. 